\title{
PERFORMANCE MEASUREMENT USING A NOVEL DIRECTIONAL DISTANCE FUNCTION BASED SUPER EFFICIENCY MODEL AND NEIGHBOURHOOD THEORY
}

\author{
SUBHADIP SARKAR* (10
}

\begin{abstract}
This paper entails a systematic approach for measuring the Super Efficiency Scores of a set of rival firms. This evaluation process is dependent on the location of the worst Decision-Making Unit retained by the technology set. Unlike antecedent researches, the worst point is selected from a predefined neighbourhood with an application of a linear model. Finally, the new Super Efficiency model measures the Efficiency score while embedding the worst point within the direction vector. This two-stage model is akin to the standard form of a Directional Distance Function and does not end up with problems of infeasibility, negative data or zero data. In other words, the method is found robust to classify the Decision Making Units into the Super-Efficient, Strongly Efficient, Weakly Efficient and Inefficient groups. Two cases once addressed by Seiford and Zhu [INFORS 37 (1999) 174-187.] and Byrnes et al. [Manag. Sci. 30 (1984) 671-681.] are illustrated here to explore the functionality of the model in comparison to a few renowned ones.
\end{abstract}

Mathematics Subject Classification. 90C08.

Received: March 10, 2021. Accepted October 26, 2021.

\section{INTRODUCTION}

Measurement of "Super-Efficiency (SE)" for Decision-Making Units (DMUs) in Data Envelopment Analysis (DEA) is needed to rank the efficient DMUs who achieve unity as an efficiency score ([5]; Cooper et al., 2000). SE method excludes the DMU under evaluation from the reference set so that efficient DMUs may have efficiency scores larger than or equal to 1, and inefficient DMUs have identical efficiency scores as those obtained from the CCR model. Ranking of the best performers was made possible by several methods authored by Andersen and Petersen [1], Doyle and Green [10,11], Stewart [29], Tofallis [31], Seiford and Zhu [27], and Zhu [36]. Tone [32] used a non-radial format to compute a slacks-based measure of efficiency (SBM). In this context, the additive integer-valued and additive SE integer-valued models of Du et al. [12], partial frontier analysis by Gnewuch and Wohlrabe [14] or the additive SE model of Yu and Hsu [34] are worth mentioning.

However, the crisis of infeasibility became evident when few special DMUs failed to trace a peer on the production frontier during their assessments made by the VRS based SE model ([22]; Chen, [6]). Lovell and Rouse (LR) modified the standard DEA model to overcome the infeasibility problem for computing SE for a few

Keywords. Data Envelopment Analysis, Super Efficiency Score, Directional Distance Function, infeasibility problem, neighbourhood theory.

National Institute of Technology, Mahatma Gandhi Avenue, Durgapur 713209, India.

*Corresponding author: subhadip9775@gmail.com 
Strongly Super-Efficient DMUs [33]. LR approach appropriately scales up the observed input vector (scale down the output vector) of the relevant super-efficient firm to create its inefficient surrogate. Ray [26] demonstrated an alternative way to use the directional distance function and the resulting Nerlove-Luenberger (NL) measure of SE. This measure was shown to be unique and did not depend on any arbitrary choice of a scaling parameter. The approach of Cook et al. [9] could offer a feasible and optimal solution for the super-efficient DMUs that can cause infeasibility under the erstwhile SE models.

The two-stage model of Lee et al. [17] showed that the infeasibility could creep into the input-oriented (output-oriented) model due to the existence of any output surplus (input saving). The SE score was expressed in combination with both the radial efficiency and output surplus (input saving) attribute. Chen and Liang [8] further solved the two-stage process using a single-stage linear program. The researches of Lin and Chen [19], Lin and Chen [20], Lin and Liu [21] etc., later on, claimed to offer remedies to the so-called "Infeasibility, zero data and negative data" problems using the concepts of Directional Distance Function (DDF).

On the other hand, the zero data problem emerges for those DMUs which contain zeros in their input-output bunches. For example, Thrall [30] and Zhu [35] earlier detected the infeasibility problem when zero input values were treated within the CRS SE model. Ray [26] warned about this fallacy within the NL based SE model owing to its direct impact on the direction vector. Lee and Zhu [18], moreover, pointed out the ineffectiveness of the models prescribed by Lee et al. (2011) and Chen and Liang [8] even in zero data. The authors showed the applicability of their model for solving problems under CRS as well as VRS assumptions.

In DEA deriving a solution to a negative-data problem has been a challenge as the initial postulates were constructed based on the positive data. Several models ([13,16,23-25, 28] etc.) were applied to handle them. Hadi-Vencheh and Esmaeilzadeh [15] modified the Range Directional Model (RDM) [25] to generate SE scores without incurring the infeasibility problem. The models of Lin and Chen [19], Lin and Chen [20], Lin and Liu [21] etc., were found reasonably effective for treating the negative data.

However, despite having advantages, these approaches failed to create a standard way of selecting the direction vector to locate the peer and its impact on the SE score. For example, few models even found negative numbers to reach the frontier along the direction vector while moving from the SE DMU. Some techniques could not succeed to resolve the infeasibility issues. In the case of the zero data, some models gave rise to the SE scores solely dependent on the model parameters [20]. Some renowned models failed to compute the input saving index and output surplus index values under these circumstances. The extant research aims to develop a more rational and comprehensive procedure that can eliminate all these issues. In this context, the theme of the worst point is proposed in this paper to resolve the infeasibility crisis. It also provides a unique way of computing radial input slack index and output surplus index values which will remain effective for negative or zero data.

In this regard, the subsequent sections are going to highlight the following aspects. Section 2 provides a brief description of the traditional models to compute the SE scores and the ways to resolve the infeasibility crisis. Section 3 addresses the solution to remove this issue using a two-stepped approach. This section also depicts the need of defining and obtaining a Worst Point and its impact on the SE score. Section 4 describes a comparative study for the sake of appraisal of the new model. Finally, the last section provides the concluding remark about it.

\section{Description of Super EfFiciency models}

Let there be a technology set $T$ with $c$ observed DMUs where each produces the same $v$ outputs in diverse amounts using the same $m$ inputs in different amounts. Any feasible unit $r(=1,2, \ldots, c)$ which is also a member of $T$ consumes a desirable input $x_{r}$ to produce a desirable output $y_{r}$. In other words, the production system is depicted as:

$$
T=\left\{(x, y): y \geq \sum_{r=1}^{c} x_{r} \lambda_{r} ; y \leq \sum_{r=1}^{c} y_{r} \lambda_{r} ; \lambda_{r} \geq 0\right\}
$$

where $x_{r}=\left(\begin{array}{llll}x_{1 r} & x_{2 r} & \ldots & x_{m r}\end{array}\right) \in \boldsymbol{R}_{\boldsymbol{m}}^{+}, y_{r}=\left(\begin{array}{llll}y_{1 r} & y_{2 r} & \ldots & y_{v r}\end{array}\right) \in \boldsymbol{R}_{\boldsymbol{v}}^{+}$. 
Inputs (outputs) are assumed to be freely disposable and $T$ should contain any bunch of input-output $\left(x^{\prime}, y^{\prime}\right)$ satisfying $x^{\prime} \geq x$ and $y^{\prime} \leq y$. In addition to that, for any chosen value of $k \geq 0(k x, k y)$ is feasible when the bunch $(x, y)$ is feasible. DMU o is called efficient if there exists no unit $\left(x^{\prime}, y^{\prime}\right) \in T$ such that $x_{o} \geq x^{\prime}$ and $y_{o} \leq y^{\prime}$ where $\left(x_{o}, y_{o}\right) \neq\left(x^{\prime}, y^{\prime}\right)$. To support a Constant Returns to Scale (CRS) a Production Possibility Set (PPS) in this regard, is expressed mathematically as the formulation mentioned in (2.1):

$$
\begin{array}{ll}
\sum_{r=1}^{c} x_{i r} \lambda_{r} \leq x_{i o}, & i=1,2, \ldots, m \\
\sum_{r=1}^{c} y_{j r} \lambda_{r} \geq y_{j 0}, & j=1,2, \ldots, v \\
\lambda=\left[\begin{array}{llll}
\lambda_{1} & \lambda_{2} & \cdots & \lambda_{c}
\end{array}\right]^{T},\left(\lambda_{r} \geq 0, \forall r\right) . &
\end{array}
$$

To involve an assumption of Variable Returns to Scale (VRS) here requires an additional constraint $\sum_{r=1}^{c} \lambda_{r}=1$, for $r=1,2, \ldots, c$.

\subsection{Standard SE-BCC models}

The Input Oriented Super-Efficiency score of the DMU o (which is a member of the PPS $T$ defined above) is computed from the following VRS super-efficiency model:

$$
\begin{array}{ll}
\sum_{\substack{r=1 \\
r \neq 0}}^{c} x_{i r} \lambda_{r} \leq \beta x_{i o}, & i=1,2, \ldots, m \\
\sum_{\substack{r=1 \\
r \neq 0}}^{c} y_{j r} \lambda_{r} \geq y_{0}, & j=1,2, \ldots, v \\
\sum_{\substack{r=1 \\
r \neq 0}}^{c} \lambda_{r}=1, \lambda_{r} \geq 0, \quad \text { for } \quad r=1,2 \ldots, c, r \neq o . \\
\end{array}
$$

Here, the DMU o under evaluation is excluded from the reference set. When DMU o is efficient and model (2.2) is feasible, then $\beta>1$ is indicative of the way the DMU o has to increase its input vector to reach the frontier formed by the rest of the DMUs. Similarly, the output-oriented VRS super-efficiency model can be expressed as follows:

$$
\begin{aligned}
& \operatorname{Max} \beta \\
& \sum_{\substack{r=1 \\
r \neq 0}}^{c} x_{i r} \lambda_{r} \leq x_{i o}, \quad i=1,2, \ldots, m \\
& \sum_{\substack{r=1 \\
r \neq o}}^{c} y_{j r} \lambda_{r} \geq \beta y_{j o}, \quad j=1,2, \ldots, v \\
& \sum_{\substack{r=1 \\
r \neq o}}^{c} \lambda_{r}=1 ; \lambda_{r} \geq 0 \quad \text { for } \quad r=1,2, \ldots, c \quad \text { and } r \neq o
\end{aligned}
$$

when DMU o is efficient and model (2.3) is feasible, $\beta<1$, indicating that DMU o's outputs are decreased to reach the frontier formed by the convex combination of the rest of DMUs. But, equations (2.2) and (2.3) was found infeasible when analysing a special type of VRS efficient DMU. 


\subsubsection{The problem of infeasibility in the SE-BCC model}

Referring to the propositions of Xue and Harker [33] the crisis of infeasibilities are seen in the following cases:

If DMU-O is strongly super-efficient in the input-oriented VRS super-efficiency DEA model, the primal model for DMU-O is infeasible. In the primal (the corresponding dual problem) input-oriented VRS superefficiency DEA model for a DMU-O is infeasible (unbounded) if and only if DMU-O is super-efficient in the input-oriented VRS super-efficiency DEA model.

These exceptional individuals are those which can outperform others based on the usage of inputs or generation of outputs. In case of the first (second) type at least one input (output) will concluded that the root of this problem remains with the strongly super-efficient DMUs. A strongly super-efficient DMU is defined as " $a$ $D M U-O$ that strictly exceeds any other DMU in at least one dimension of the output (input) vector in model (2.2) ((2.3))".

\subsection{Standard Directional Distance Function to compute SE score}

To detect the inefficiency of a DMU, Directional Distance Function was conceived by Chambers et al. [4]. It was derived based on Luenberger's benefit function to obtain a measure of technical efficiency reflecting the potential for increasing outputs while reducing inputs simultaneously. To measure the Super Efficiency Score of a DMU an extended form of the DDF model is also found relevant (shown in (2.4)). Equation (2.4) utilises a reference input-output bundle $\left(g_{X}, g_{Y}\right)$ to reach a production frontier from some input-output bundle $\left(x_{o}, y_{o}\right)$. Concerned with the PPS, $T$, the directional distance function is defined as:

$$
D\left(x_{o}, y_{o}, g_{X}, g_{Y}\right)=\max \beta:\left\{\left(x_{o}+\beta g_{X}, y_{o}-\beta g_{Y}\right) \in T\right\} \quad \forall \beta \in R^{ \pm}
$$

when $T=\left\{(x, y): x \geq \sum_{\substack{r=1 \\ r \neq o}}^{c} x_{r} \lambda_{r}, y \leq \sum_{\substack{r=1 \\ r \neq 0}}^{c} y_{r} \lambda_{r}, \sum_{\substack{r=1 \\ r \neq o}}^{c} \lambda_{r}=1\right\}$.

These direction vectors must fulfil certain properties [4].

$$
\begin{aligned}
& \operatorname{Min} \beta \\
& \sum_{\substack{r=1 \\
r \neq 0}}^{c} x_{i r} \lambda_{r}-\beta g_{i X} \leq x_{i o}, \quad i=1,2, \ldots, m \\
& \sum_{\substack{r=1 \\
r \neq 0}}^{c} y_{j r} \lambda_{r}+\beta g_{j Y} \geq y_{j o}, \quad j=1,2, \ldots, v, \beta \in R^{ \pm} \\
& \sum_{\substack{r=1 \\
r \neq 0}}^{c} \lambda_{r}=1, \lambda_{r} \geq 0 \quad \text { for } \quad r=1,2, \ldots, c, r \neq o .
\end{aligned}
$$

An optimal solution $\beta>0$ is indicative of the presence of a super-efficient (Nerlove-Luenberger (NL)) DMU O. Barring this, it would suggest to scale down (up) the output (input) bundle of DMU O to get an attainable input-output bundle in the modified PPS. A firm achieves a superior rank between two firms on basis of the higher value of $\beta$.

RDM [25] has also its limitation to resolve the infeasibility issue. Example 1 is added here to (using Tab. 1 and Fig. 1a) show that during the measurement of SE score of $E$ the line (IE) connecting it with the Best

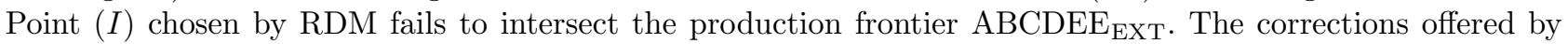
Hadi-Vencheh and Esmaeilzadeh [15] indeed created the way of applying RDM to determine the Super Efficiency Scores while selecting a reference point from the set $T /\left(x_{0}, y_{0}\right)$. However, the solution was not free from glitches (Fig. 1b). 
TABle 1. Data set.

\begin{tabular}{lll}
\hline \hline DMU & Input & Output \\
\hline A & 6 & 1 \\
B & 7 & 3 \\
C & 9 & 5 \\
D & 10 & 6 \\
E & 13 & 7 \\
F & 14 & 6 \\
\hline
\end{tabular}

The model of Cook et al. [9] features another form of a directional distance function (shown below in (2.5) (input-oriented form)) for measuring SE score under VRS where needed improvements on the input and output vectors are sought unequally (as $\beta$ and $\alpha$ are used separately). DMUs having problems with their output constraints in Input Oriented VRS SE model succeeded to attain a Super Efficiency Score.

$$
\begin{array}{ll}
\sum_{\substack{r=1 \\
r \neq o}}^{c} x_{i r} \lambda_{r} \leq(1+\beta) x_{i o}, & i=1,2, \ldots, m \\
\sum_{\substack{r=1 \\
r \neq o}}^{c} y_{j r} \lambda_{r} \geq(1-\alpha) y_{j o} & j=1,2, \ldots, v ; \beta \in R^{ \pm} \\
\sum_{\substack{r=1 \\
r \neq o}}^{c} \lambda_{r}=1, \lambda_{r} \geq 0 & \text { for } \quad r=1,2, \ldots, c ; r \neq o .
\end{array}
$$

The expression mentioned below was introduced to compute the input-oriented SE score:

$$
\mathrm{SE}_{o}=(1+\beta)+\frac{1}{(1-\alpha)} .
$$

Lin and Chen [19] (LC) criticised the model proposed by Chen et al. [7] for its lack of strength to remove the infeasibility crisis completely and employed a direction vector given as:

$$
\left[\left\{\left(\max _{r \neq o} x_{i r}+x_{i o}\right), y_{j o}\right\}, \forall i, j\right] .
$$

The model of Lin and Chen [20] (shown below) revealed the inabilities of the NL and LC:

$\operatorname{Max} \beta$

$$
\begin{array}{ll}
\sum_{\substack{r=1 \\
r \neq o}}^{c} x_{i r} \lambda_{r} \leq(1-\beta) x_{i o}-\beta a_{i}, & i=1,2, \ldots, m \\
\sum_{\substack{r=1 \\
r \neq o}}^{c} y_{j r} \lambda_{r} \geq(1+\beta) y_{j o}-\beta b_{j} & j=1,2, \ldots, v ; \beta \in R^{ \pm} \\
\sum_{\substack{r=1 \\
r \neq o}}^{c} \lambda_{r}=1, \lambda_{r} \geq 0 & \text { for } \quad r=1,2 \ldots, c ; r \neq o
\end{array}
$$




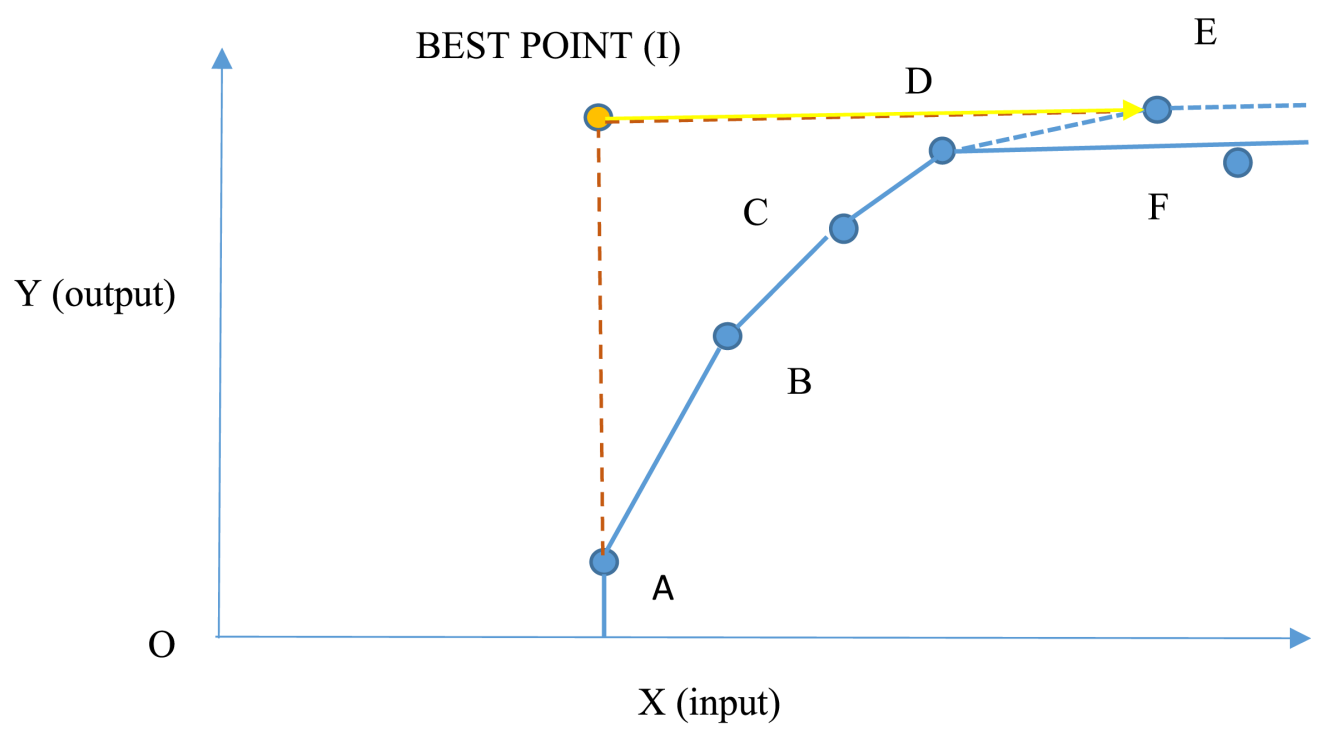

(a)

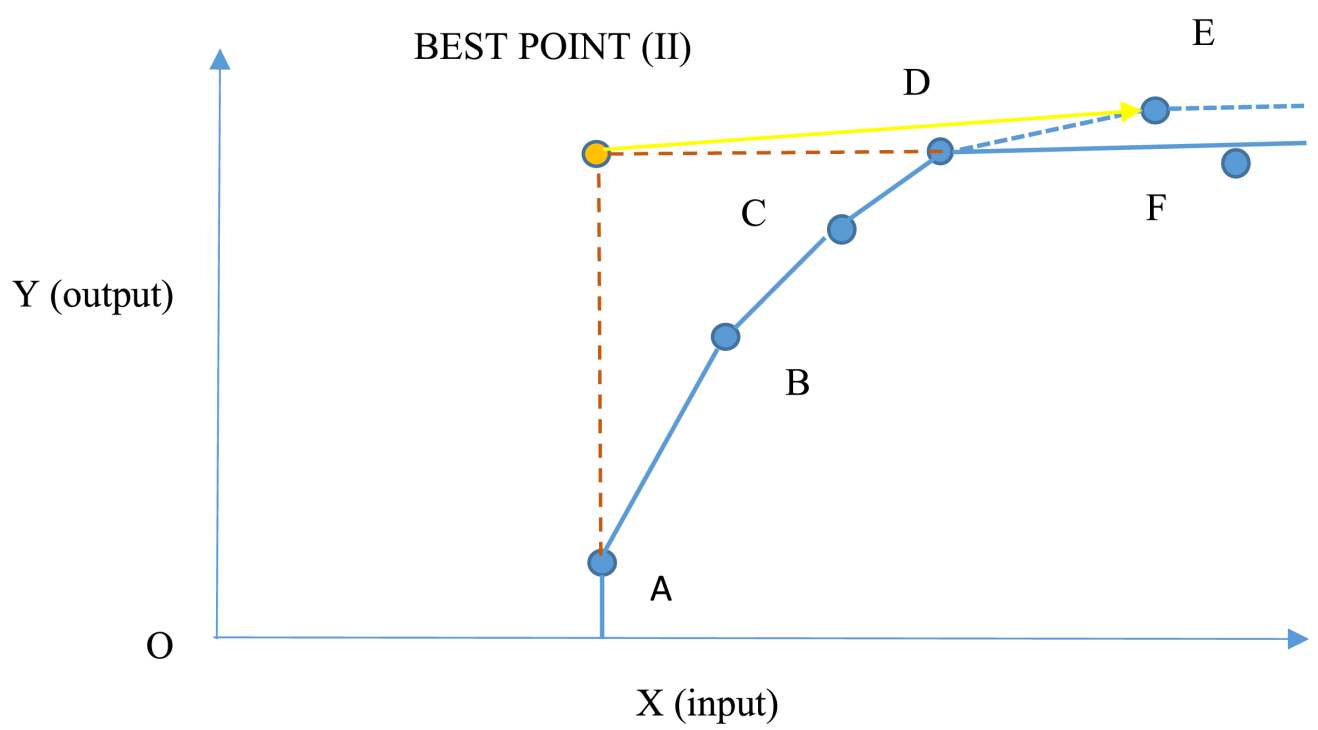

(b)

Figure 1. (a) Failure of RDM. (b) Failure of the alternative model of Hadi.

$$
\begin{array}{rlrl}
a_{i} & =k\left(\max _{r} x_{i r}\right), k \geq 3, & \forall i, r, \\
b_{j}=\left(\min _{r} y_{j r}\right), & \forall j, r .
\end{array}
$$

Hence, the entire research is hovering around the choice of selecting the reference point and the pair of direction vectors which could be relevant tool to treat positive as well as negative data. In this direction the new research is going to put few important inquisitions about the way of selecting the value of $k$. What is the implication of 
selecting a higher or lower value of it? For example, the input and output constraints of (2.6a) can be rearranged in the following manner:

$$
\begin{aligned}
& \sum_{\substack{r=1 \\
r \neq o}}^{c} x_{i r} \lambda_{r} \leq x_{i o}-\beta\left(a_{i}+x_{i o}\right), \quad i=1,2, \ldots, m \\
& \sum_{\substack{r=1 \\
r \neq o}}^{c} y_{j r} \lambda_{r} \geq y_{j o}+\beta\left(y_{j o}-b_{j}\right) \quad j=1,2, \ldots, v ; \beta \in R^{ \pm} .
\end{aligned}
$$

Selection of two different values are set for $k$ can have an impact on the efficiency scores on the SE score of the DMU. So, is it a robust way of choosing a direction vector?

In this regard, the concept of a Worst Point is approved so that a direction be proposed which will be consistent with the positive as well as negative data. Apart from that the impact of such a selection on the SE score is needed to be explored.

\section{Proposed SOlution to The infeAsibility PROBlem}

One reason for having a crisis of infeasibility is due to the selection of an inappropriate direction vector which ultimately fails to find a suitable point on the frontier. To place a curb on this matter a new vector is proposed which will be emanating from a technologically feasible Worst Point and ending at the DMU which is under consideration. In this context, there can be two possibilities that will help in deciding the location of the peer on the frontier. In the first case, if the DMU is Strongly Efficient then it will be away from the legitimate boundary of the convex set $T$. Hence, the peer will certainly create an internal division on the line joining the worst point and the stated DMU. The subsequent theorems are added in favour of this case:

Theorem 3.1. The line segment connecting two points that remain at the interior and exterior to a Production Possibility Set $T$ will find an element located on the closure of $T$.

Proof. Let there be two points $A_{0}$ and $A_{w}$ which are external and internal to the production possibility set $T$. Then according to the definitions of the exterior and interior points there must a few positive numbers $\varphi_{0}$ and $\varphi_{w}$ such that the following conditions can prevail:

$$
\begin{array}{ccl}
\left\|A_{0}-b_{0}\right\|<\varphi_{0} & \text { and } & \left\|A_{w}-b_{w}\right\|<\varphi_{w} \\
N_{\varphi_{0}}\left(A_{0}\right) \subset T^{c} & \text { and } & N_{\varphi_{w}}\left(A_{w}\right) \subset T .
\end{array}
$$

Here, $N_{\varphi_{0}}\left(A_{0}\right)$ denotes the neighbourhood of $A_{0}$. Let there be another point $A_{p}$ which is situated on the boundary of $T$ such that due to a variable $\vartheta \in(0,1)$ the following linear relationship is fulfilled:

$$
A_{p}=\vartheta A_{0}+(1-\vartheta) A_{w} .
$$

In addition to this, for any point $c_{p}$ a couple of relationships can be conceived:

$$
\begin{aligned}
& \left\|A_{p}-c_{p}\right\|<\varphi_{p} \text { where } \varphi_{0}<\varphi_{p} \text { and } \varphi_{w}<\varphi_{p} \\
& N_{\varphi_{p}}\left(A_{p}\right) \cap T^{c} \neq \emptyset \text { and } N_{\varphi_{p}}\left(A_{p}\right) \cap T \neq \emptyset .
\end{aligned}
$$

In this case $c_{p}$ can either be within $T$ or $T^{c}$. Now, if it is subsumed that there exists a variable $\vartheta$ such that another point $b_{p}$ is obtained using a linear combination of $b_{0}$ and $b_{w}$ :

$$
b_{p}=\vartheta b_{0}+(1-\vartheta) b_{w} .
$$

Now, $\left\|A_{p}-b_{p}\right\|=\left\|\vartheta A_{0}+(1-\vartheta) A_{w}-\vartheta b_{0}-(1-\vartheta) b_{w}\right\|$ (from (3.2))

$$
\left\|\vartheta\left(A_{0}-b_{0}\right)+(1-\vartheta)\left(A_{w}-b_{w}\right)\right\|<\vartheta\left\|A_{0}-b_{0}\right\|+(1-\vartheta)\left\|A_{w}-b_{w}\right\|=\vartheta \varphi_{0}+(1-\vartheta) \varphi_{w}<\varphi_{p} .
$$

But, equation (3.5) implies that $b_{p}$ exists in the neighbourhood of $A_{p}$. Thus, the theorem is proved. 
The second theorem is referred below in connection to an Inefficient DMU.

Theorem 3.2. The line segment connecting two points that remain at the interior to a Production Possibility Set $T$ will find a peer on the boundary of $T$.

Proof. For any convex set $S\left(\subset R^{n}\right)$ with a nonempty interior if there exist two elements $A_{1}$ and $A_{2}$ such that $A_{1} \in \operatorname{cl}(S)$ and $A_{2} \in \operatorname{int}(S)$, then, the convex combination of these points will remain within the interior of $S$. In other words, $A=\lambda A_{1}+(1-\lambda) A_{2} \in \operatorname{int}(S)$ for $1 \geq \lambda>0$ (the proof is mentioned in the book of [2]). This proposition also confirms that if two points $A \in \operatorname{int}(S)$ and $A_{2} \in \operatorname{int}(S)$ are connected with a line then the extension of the line will find a point on the boundary of $S$. In this case, the point seems to be situated on the boundary due to an appropriate selection of $\lambda \forall A_{1}=\frac{1}{\lambda}\left[A-(1-\lambda) A_{2}\right]$. Hence, this is the only matter that has to be shown to prove the theorem.

Let there be a convex set $S$ and there are two points $B$ and $A_{1}$ such that $B \in \operatorname{ext}(S)$ and $A_{1} \in \operatorname{int}(S)$. It is then possible to locate another point $\bar{A} \in \operatorname{cl}(S)$ which will have a minimum distance from $y$. An inequality is strictly held in this case is $(B-\bar{A})^{T}\left(A_{1}-\bar{A}\right) \leq 0$. Now, if there exists another point $A_{2} \in \operatorname{int}(S)$ so that for a positive value of $\rho$ the ratio $\frac{\left(A_{1}-\bar{A}\right)}{\left(A_{2}-\bar{A}\right)}=\rho$ is held. In other words, $A_{2}\left(=\frac{1}{\rho}\left[\bar{A}-(1-\rho) A_{2}\right]\right)$ will be situated on the same line joining two points $A_{1}$ and $\bar{A}$. A positive value of $\rho$ is an indicator of an external division of the line created by $A_{1}$ and $A_{2}$. This equivalence will end up with the inequality $(B-\bar{A})^{T}\left(A_{2}-\bar{A}\right) \leq 0$. This condition affirms that even if another point was chosen from the line joining $A_{1}$ and $\bar{A}$ then also $B$ and $\bar{A}$ shall have the minimum distance. Hence, the proof of the Theorem 3.2 is complete.

\subsection{Example 2 to show the way to measure SE}

The assessment of SE score is illustrated here with Example 2. Let there be a Production Possibility Set containing three DMUs say $A$ (Efficient), $B$ (Inefficient) and $R$ (Worst Point) having their input-output vectors of $(4,6),(6,5)$ and $(8,4)$, respectively. Then to compute the SE score of $A$, it has to be kept outside the convex zone defined by $B$ and $R$. The current peer $B$ will be located at the boundary of the zone to create an internal division (with a ratio of $(1-\tau: \tau) \forall 1 \geq \tau>0)$ of the line segment $A R . \tau$ is computed from the following ratio:

$$
\tau=\frac{B R}{A R}=\frac{8-6}{8-4}=\frac{6-5}{6-4}=\frac{1}{2} .
$$

But, the SE score of $A$ is given by: $\mathrm{SE}_{A}=\frac{A R}{B R}=2$. Similarly, the SE score of $B$ is obtained from the $\mathrm{SE}_{B}=\frac{B R}{A R}=\frac{1}{2}$. However, in this case, point $A$ has to create an external division to the line segment $B R$ (with a ratio of $(\tau-1: \tau) \forall 1<\tau)$. The value of $\tau$ is computed from the ratio $\tau=\frac{A R}{B R}=2$.

This small example narrates the fact that $\tau$ will certainly possess a positive score even though the DMU is located within the convex zone or not. The SE score will be $\frac{1}{\tau}$ irrespective of the score possessed by $\tau$. Moreover, $\tau$ has the greatest lower bound which is solely dependent on the location of $R$. The more it moves towards $B$ the more will be the SE score of $A$ and the less will be the SE score of $B$. To incorporate this concept into a real-life problem four major steps are adopted to measure SE for a DMU (subsequent sections will sequentially illustrate them):

- To define the neighbourhood within which the Worst Point is to be located.

- To select a Worst Point within the span of the neighbourhood using a Linear Model-1.

- To apply the Linear Model-2 on a DMU to determine the model parameter.

- To find SE of a DMU using the optimal value of the model parameter.

\subsection{Definition of Worst Point}

The vector $\left(x_{I}, y_{I}\right)$ is designated as the "Worst Point" to exemplify a firm that consumes the highest amount of inputs to deliver the lowest possible outputs (in comparison to the current set of DMUs).

$$
x_{I}=\left[\begin{array}{llll}
x_{1 I} & x_{2 I} & \ldots & x_{m I}
\end{array}\right], \quad y_{I}=\left[\begin{array}{llll}
y_{1 I} & y_{2 I} & \ldots & y_{v I}
\end{array}\right]
$$


where, $x_{i I}>x_{i o}, \forall i$ as $x_{i I}=\left(\max _{r} x_{i r}+\delta\right)>\max _{r} x_{i r} \geq x_{i o}$, for $\forall i, \delta>0, y_{j o}>y_{j I}, \forall j$ as $y_{j I}=$ $\left(\min _{r} y_{j r}-\delta\right)<\min _{r} y_{j r} \leq y_{j o}$, for $\forall j, \delta>0$.

The worst member is obtained for any positive value of $\delta$. The inception of $\delta$ will eliminate the chance of having a DMU to become the worst member of the Production Possibility Set. Hence, for a least upper bound $2 \delta^{\prime}$ of $\delta \forall \delta \leq 2 \delta^{\prime}$ there will be a set of worst points each of which can emerge as a candidate for becoming a perfect reference point.

Definition. For a given Production Possibility Set $T$ a $\delta$-worst member is the one which will be the element of the set defined by $N_{\delta^{\prime}}\left(x_{I}, y_{I}\right)$.

Now the following proofs are instrumental to display that the worst point situated inside a convex set will trace a peer on the frontier (or on the extended frontier) when connected with a DMU (located inside or outside the zone) with the aid of a straight line.

Theorem 3.3. During the Measurement of SE of a VRS efficient DMU a peer will always be obtained on the frontier or extended frontier if it (the VRS efficient DMU) is connected with a Worst Point which is Technologically Feasible.

Proof. Let there be a hypothetical DMU which consumes $x_{i I}=\left(\max _{r} x_{i r}+\delta\right) \forall i, \delta>0$ to generate output $y_{j I}=\left(\min _{r} y_{j r}-\delta\right) \forall j, \delta>0$. With this designed DMU each of these two constraints will be ascertained.

$$
\begin{array}{ll}
x_{i I}>x_{i o}, \forall i \text { as } x_{i I}=\left(\max _{r} x_{i r}+\delta\right)>\max _{r} x_{i r} \geq x_{i o}, & \text { for } \forall i, \delta>0 \\
y_{j o}>y_{j I}, \forall j \text { as } y_{j I}=\left(\min _{r} y_{j r}-\delta\right)<\min _{r} y_{j r} \leq y_{j o}, & \text { for } \forall j, \delta>0 .
\end{array}
$$

The point $\left(x_{I}, y_{I}\right)$ will be feasible in $T$ due to the rules stated in (2.1) and can be counted as an interior point as a neighbourhood $N_{\delta}\left(x_{I}, y_{I}\right)$ is clearly defined for it so that $N_{\delta}\left(x_{I}, y_{I}\right) \subset T$. Hence, this interior point can be effectively termed as the Worst Point within $T$ and is suitable for the appraisal of measuring SE of the DMUs. Moreover, employing the Theorem 3.2 it can be stated that any vector connecting the SE DMU with the Worst Point will definitely produce an intersecting point on the boundary or extended boundary of the production frontier. Hence, there will be no infeasibility problem. But, unlike choosing an arbitrary reference point [20] a point is selected after solving a linear problem.

\subsubsection{Selection of a Worst Point within the neighbourhood using a Linear Model-1}

The value of $\delta(>0)$ is derived from the linear model described below:

$$
\begin{array}{ll}
\operatorname{Max} \delta & \\
\sum_{r=1}^{c} x_{i r} \lambda_{r} \leq \tau x_{i \max }+(1-\tau)\left(x_{i \max }+\delta\right), & i=1,2, \ldots, m \\
\sum_{r=1}^{c} y_{j r} \lambda_{r} \geq \tau y_{j \min }+(1-\tau)\left(y_{j \min }-\delta\right), & j=1,2, \ldots, v \\
\bar{x}_{i o}=x_{i \max }+\delta, \text { where } x_{i \max }=\max _{r} x_{i r} & \\
\bar{y}_{j o}=y_{j \min }-\delta, \text { where } y_{j \min }=\min _{r} y_{j r} & \\
\tau=10 & \forall r, \\
\sum_{r=1}^{c} \lambda_{r}=1, \lambda_{r} \geq 0, &
\end{array}
$$




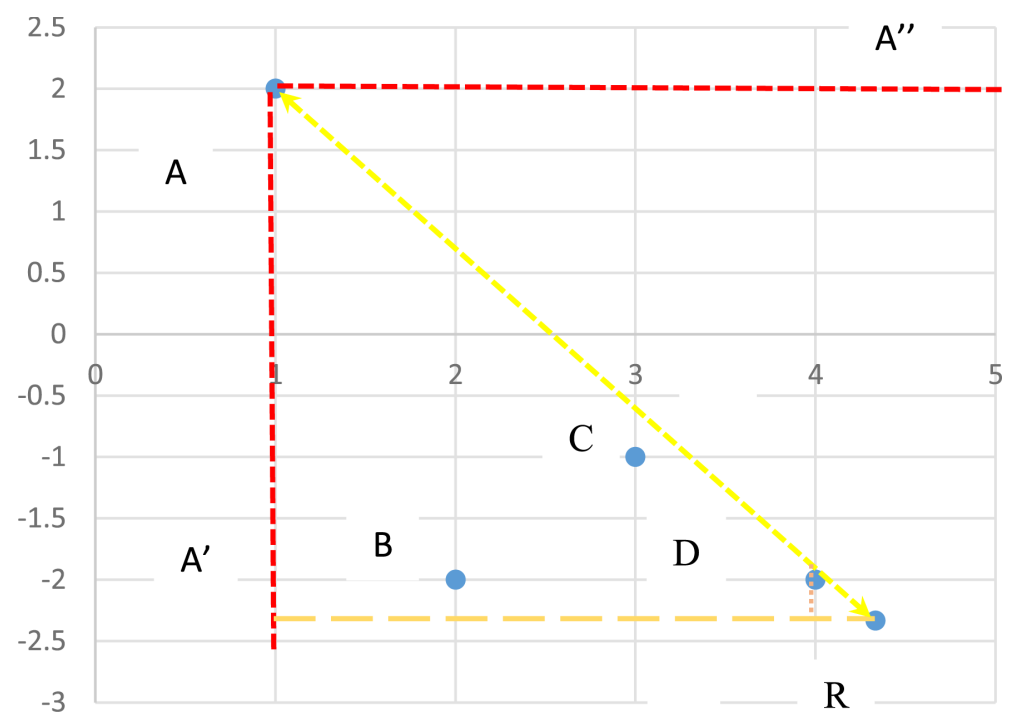

Figure 2. Example 3.

TABLE 2. Example 3 - For finding a reference point.

\begin{tabular}{lll}
\hline \hline DMU & $X$ & $Y$ \\
\hline $\mathrm{A}$ & 1 & 2 \\
$\mathrm{~B}$ & 2 & -2 \\
$\mathrm{C}$ & 3 & -1 \\
$\mathrm{D}$ & 4 & -2 \\
$\mathrm{R}$ & 4.333 & -2.333 \\
\hline
\end{tabular}

Example 3 is incorporated here to illustrate the way of selecting the optimal value of $\delta$. Figure 2 is added here to illustrate a technology involving a single-input and single-output (mentioned Tab. 2). A small value of $\delta$ establishes the equivalence $\bar{x}_{i o}=x_{i \max } \forall i$ and $\bar{y}_{j o}=y_{j \min } \forall j$.

Following the data of Table 2 it is found that DMU $A$ (among other three DMUs (say $B, C$ and $D$ )) is located on the VRS frontier $A^{\prime} A A^{\prime \prime}$ (shown in red dotted lines). The fundamental aim of using this model is to compute $\delta$ while creating a peer ( $A$ in this case) on the frontier from an external combination (by setting $\tau>1$ ) of two points $D\left(x_{\max }, y_{\min }\right)$ and $R\left(x_{I}, y_{I}\right)$. The ratio of the external division is kept constant by assigning $\tau$ a fixed quantity. Execution of the model on the data presented in Table 1 results in an optimal reference point $R$, owing to the premeditated value of $\tau=10$. As a consequence of this selection, the ratio between $|A D| /|A R|$ remains around $91 \%$. Hence, the reference point is located at the stated feasible zone.

\subsection{The proposed model}

For a proportion of division, $\tau$, and an external point $\left(x_{o}, y_{o}\right)$ (the above-mentioned set) the peer is likely to be located on the production frontier for a circumstance shown below:

$$
\beta_{o}=\min (1-\tau):\left(\tau x_{o}+(1-\tau) x_{I}, \tau y_{0}+(1-\tau) y_{I}\right) \in T /\left(x_{o}, y_{o}\right) .
$$

The model depicted in (3.6b) is suggested for deriving the optimal value of $\beta_{o}$. 
$\operatorname{Max} \tau$

$$
\begin{array}{ll}
\sum_{\substack{r=1 \\
r \neq o}}^{c} x_{i r} \lambda_{r} \leq \tau x_{i o}+(1-\tau)\left(x_{i \max }+\delta^{\prime}\right), & i=1,2, \ldots, m \\
\sum_{\substack{r=1 \\
r \neq o}}^{c} y_{j r} \lambda_{r} \geq \tau y_{j o}+(1-\tau)\left(y_{j \min }-\delta^{\prime}\right), & \tau \in R^{ \pm}, \quad j=1,2, \ldots, v \\
\sum_{\substack{r=1 \\
r \neq o}}^{c} \lambda_{r}=1, \lambda_{r} \geq 0, & \text { for } \quad r=1,2 \ldots, c, r \neq o
\end{array}
$$

$\delta^{\prime}$ is optimal value obtained from the model (3.6a) where $\tau$ is set as an unrestricted variable. It can be negative as well for those points which remains within the convex zone of $T /\left(x_{o}, y_{o}\right)$. The alternative expression of this model (3.6b) leads to another form of a DDF.

$$
\begin{aligned}
& \beta_{o}=\operatorname{Min}(1-\tau) \\
& \sum_{\substack{r=1 \\
r \neq 0}}^{c} x_{i r} \lambda_{r} \leq x_{i o}+(1-\tau)\left(x_{i \max }+\delta^{\prime}-x_{i o}\right), \quad i=1,2, \ldots, m \\
& \sum_{\substack{r=1 \\
r \neq 0}}^{c} y_{j r} \lambda_{r} \geq y_{j o}-(1-\tau)\left(y_{j o}-y_{j \min }+\delta^{\prime}\right), \quad \tau \in R^{ \pm}, \quad j=1,2, \ldots, v \\
& \sum_{\substack{r=1 \\
r \neq 0}}^{c} \lambda_{r}=1, \quad \text { for } \quad r=1,2 \ldots, c, r \neq o .
\end{aligned}
$$

Equation (3.6c) has an analogy with the standard form of DDF. The elements $\left(g_{i X}, g_{j Y}\right)$ of the Direction Vector are found to be positive (as $g_{i X}=\left(x_{i \max }+\delta^{\prime}-x_{i o}\right)$ and $g_{j Y}=\left(y_{j 0}-y_{j \min }+\delta^{\prime}\right)$ have to stay positive). The input saving index $(I s)$ and output surplus index $(O s)$ can be computed from (3.6c) using the following expressions for SE DMUs:

$$
\begin{gathered}
I s_{o}=1+\frac{1}{m} \sum_{i=1}^{m} \frac{\left[\sum_{\substack{r=1 \\
r \neq o}}^{c} x_{i r} \lambda_{r}-x_{i o}\right]}{\left[\left(x_{i \max }+\delta^{\prime}\right)-\sum_{\substack{r=1 \\
r \neq o}}^{c} x_{i r} \lambda_{r}\right]} \leq \frac{1}{\tau} \\
O s_{o}=1+\frac{1}{v} \sum_{j=1}^{v} \frac{\left[y_{j o}-\sum_{\substack{r=1 \\
r \neq o}}^{c} y_{j r} \lambda_{r}\right]}{\left[\sum_{\substack{r=1 \\
r \neq o}}^{c} y_{j r} \lambda_{r}-y_{j \min }+\delta^{\prime}\right]} \geq \frac{1}{\tau} .
\end{gathered}
$$

The expressions within (3.6d) always remain unaffected due to the zero data. However, the central issue is hovering around the justification of conceiving $\beta_{o}$ as a measure of an SE score.

\subsubsection{Interpretation of $\beta_{0}$ using Example 1}

Figures 3a-3d (drawn from Tab. 1) are instrumental to distinguish between efficient, weakly efficient, strongly efficient and inefficient DMUs under VRS. As per the data provided, five DMUs $(A, B, C, D$, and $E)$ are found strongly efficient.

According to definitions provided by Xue and Harker [33], $B$ and $D$ are categorised as Strongly Efficient DMUs whereas $C$ is marked as an efficient DMU. The location of $E(A)$ makes it special as under the output 


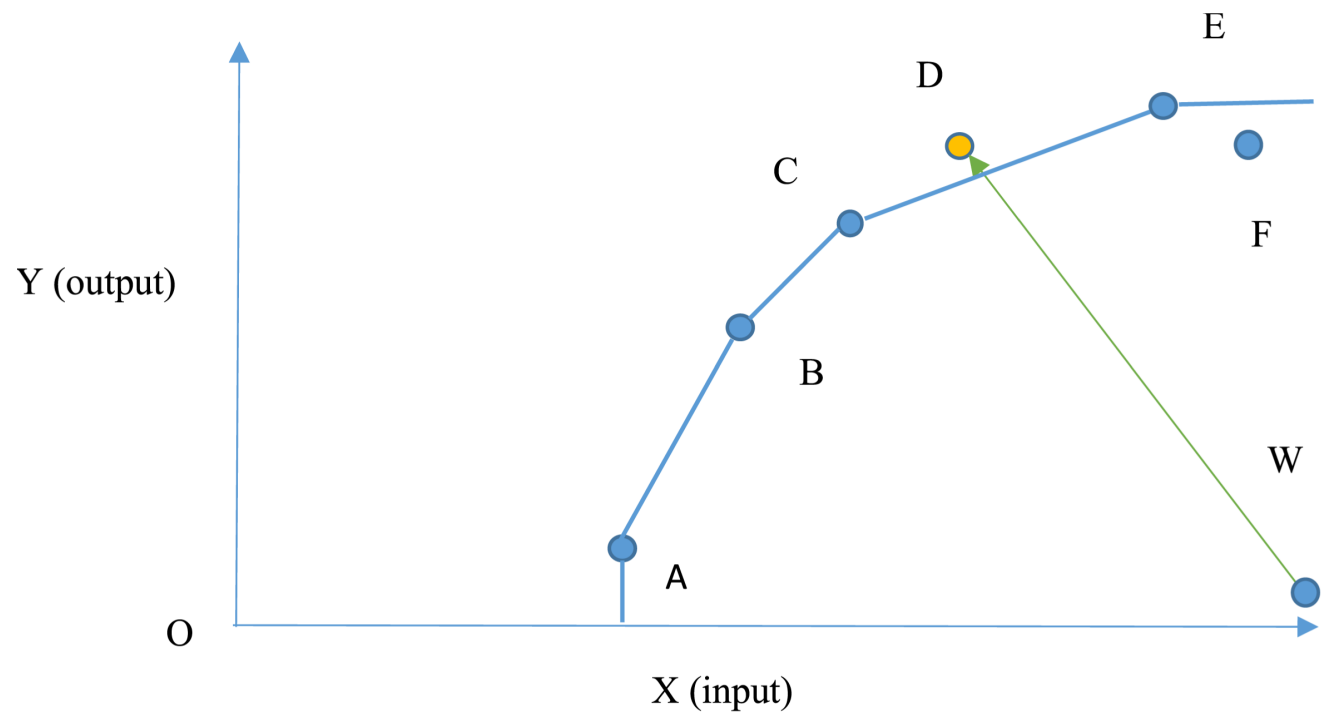

(a)

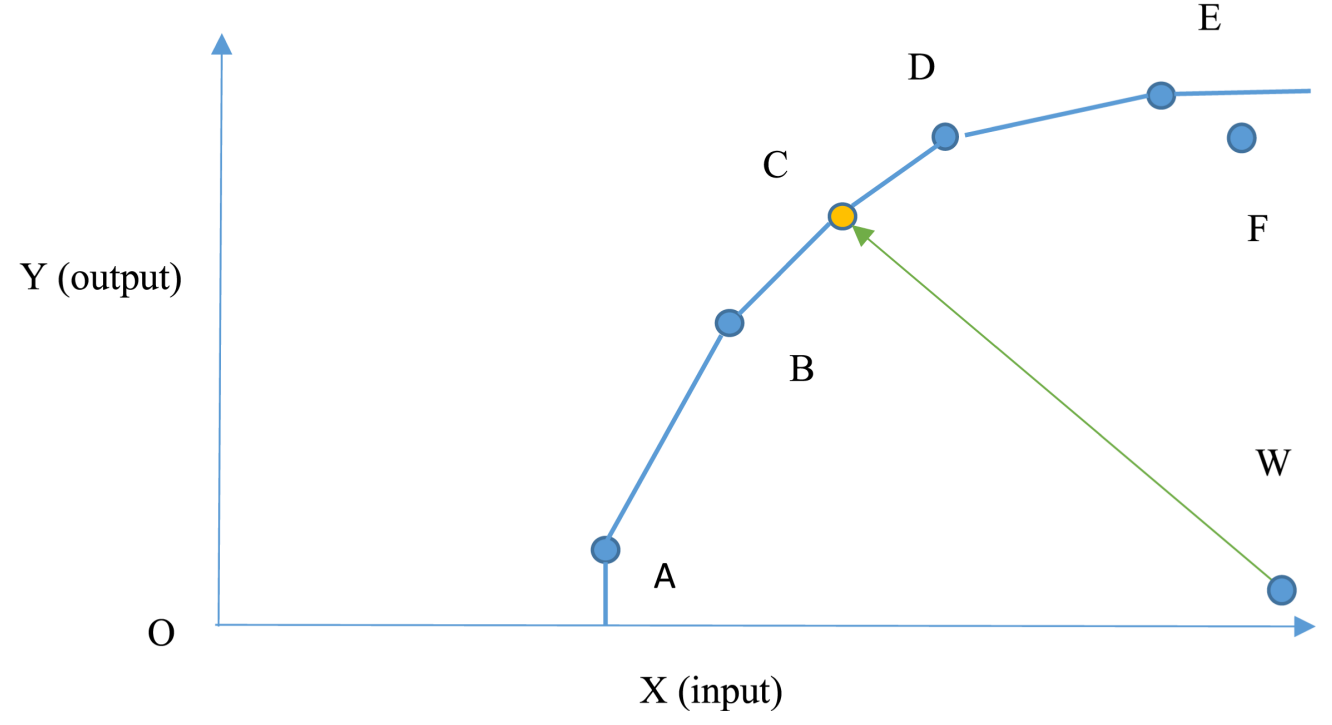

(b)

Figure 3. (a) $\beta>0$ for $D$ (Strongly Efficient). (b) $\beta=0$ for $C$ (Efficient). (c) $\beta>0$ for $E$ (Super Strongly Efficient). (d) $\beta<0$ for $F$ (Inefficient).

(input) oriented super-efficient BCC model it will certainly remain infeasible (hence is classified under Super Strongly Efficient DMU). $W$ is the worst DMU among the available set of firms which is meant for creating a reference (shown in Figs. 3a-3d).

Model (3.6b) is designed to measure the Super Efficiency Score of (say, for $D$ ) along the direction vector initiated from $W$ (say $\overrightarrow{W D}$ ). The model is built in a manner such that the optimal value of $\beta_{o}$ becomes positive when the vector needs a reduction to stay within the convex zone. In other words, following the concept of 


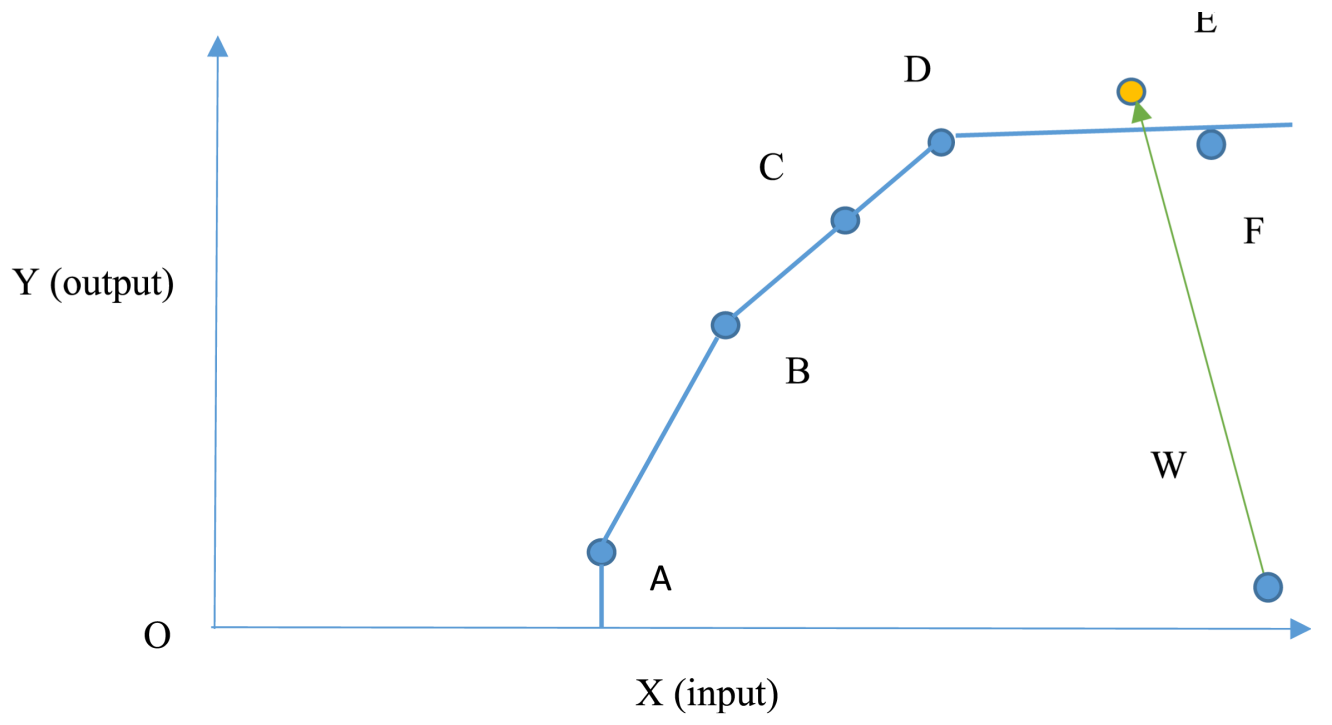

(c)

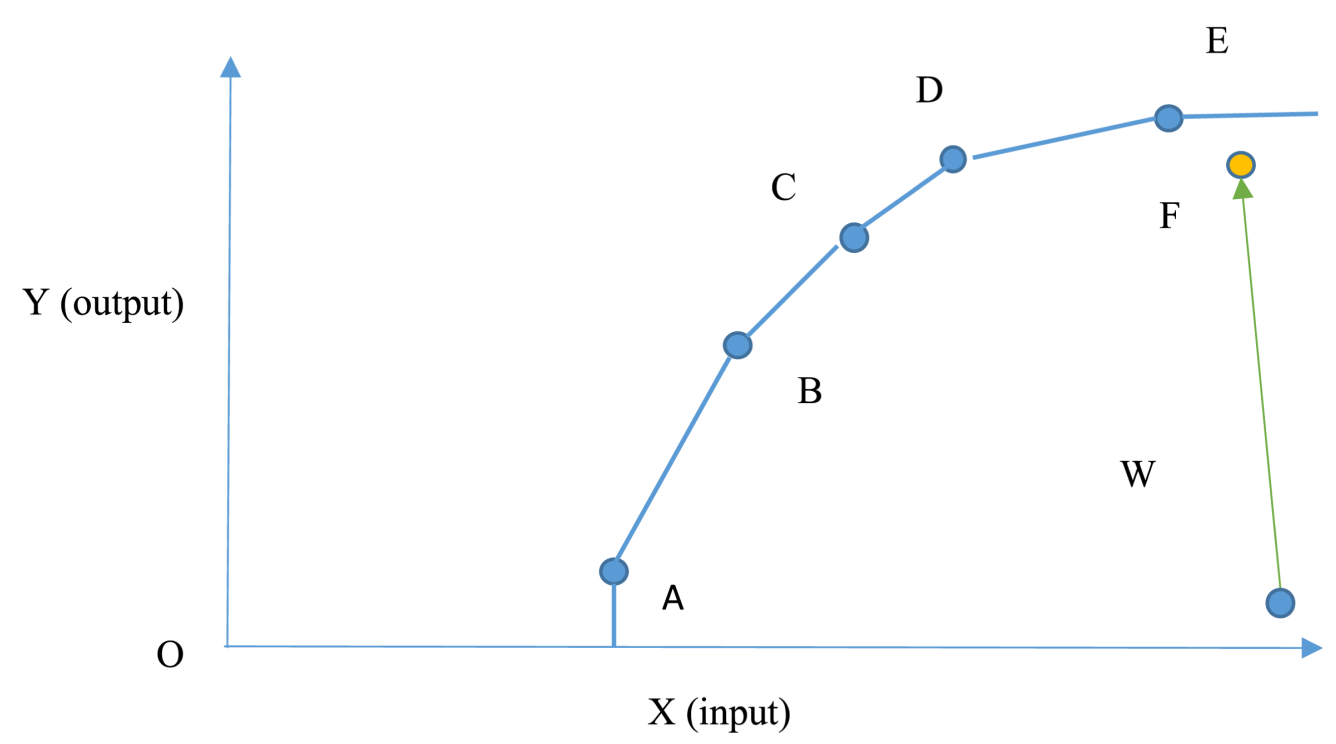

(d)

Figure 3. (Continued.)

(3.6b), it can be stated that such a peer will always remain in between the Worst Reference Point $W$ and the DMU which is under consideration. It certainly results in a positive value for $\beta_{o}$. On the contrary, it will score a negative value once it requires an extension towards the boundary defined by the production frontier. In addition to it, these figures can effectively state that an Efficient or Strongly Efficient DMU can never possess any type of slack or surplus due to inputs of outputs. In such cases, the peer appears to be constructed by the convex combination of the other efficient DMUs. However, the Super Strongly Efficient DMUs can possess slack or surplus values in their optimal solutions as the peer seems to be located on the extended portion of the frontier. 
The ways of detecting weakly efficient, strongly efficient DMUs are shown while using the following optimal values for the variables mentioned above in (3.6b) (corresponding theorems are referred in the Appendix A):

Proposition 3.4. An efficient DMU will score $\beta=0$ and have all slacks equal to 0.

Proposition 3.5. A weakly efficient DMU will score $\beta=0$ with at least one non-zero slack.

Proposition 3.6. A strongly efficient DMU will score $\beta>0$ and each slack is zero.

Proposition 3.7. A strongly Super-efficient DMU will score $\beta>0$ and have at least one non-zero slack. An output (input) oriented super strong member will certainly have at least one non-zero input (output) slack.

Proposition 3.8. An inefficient DMU will score $\beta<0$ and may or may not have a non-zero slack.

These figures consolidate the fact that exists a one-to-one relationship between the sign of $\beta$ and the vector joining the DMU under the scanner. $\beta$ attains a positive (negative) value as the arrowhead crosses (stays within) the convex zone defined by the remaining rivals. In other words, it cannot be the right terminology to express an SE score.

\subsubsection{Measurement of SE score}

It is to be noted that the ranking of DMUs can be done according to the descending order of the $\beta(>0)$ values. But, $\beta$ can never be a true measure of the SE score as it will turn into a negative quantity in case of an inefficient DMU. So, it has to be computed from (3.7):

$$
\mathrm{SE}_{o}=\left(\frac{1}{\tau}\right)=\left(\frac{1}{1-\beta}\right) .
$$

This expression of $\mathrm{SE}_{o}$ is akin to the one described in (3.6d) and it always remains positive owing to the strictly positive trait of $\tau$. It rightly indicates that the radial measure of the input savings index and output surplus index are equivalent to the SE score. Moreover, the present model does not possess any problem with the zero data points. The problem of zero data point appears when $x_{i o}=y_{j o}=0 \forall i, j$. In such cases, the total $\tau x_{i o}+(1-\tau) x_{i I}$ or $\tau y_{j o}+(1-\tau) y_{j I}$ claim non-zero values due to the second components.

\subsubsection{Elaboration with the Example 2}

This example is cited to investigate the effect of choosing the greatest lower bound of $\tau$ as 0 and keeping the worst point as $\left(x_{\max }, y_{\min }\right)$ or $(14,1)$ to compare it with the proposed model. The outputs of $(11 \mathrm{~B})$ are attached within Table 3. The optimal value of $\beta$ can therefore is derived as $(1-\beta)$.

The location of A is special as it can be classified as a super-strong efficient DMU in terms of output analysis. The optimal solution (obtained from 11B) specifies its peer as B. Moreover, the super-efficiency score is found to be 1.143 (as $\tau=0.875$ ). Most importantly, A does have slack in terms of output ( 2 units). Similar attributes can be observed for $\mathrm{E}$ as well (which is an input based super strong efficient DMU). It has not only attained a nonnegative value of $\beta 0.167$ or $(1-0.833)$ but also possesses an input based slack (3.17 units).

$\mathrm{B}$ and D are Strongly-Super-Efficient as these DMUs score non-negative optimal values of $\beta$. C shows its location on the frontier (as $\beta=0$ ) therefore it is classified under an Efficient list. On the other hand, F, apart from having an input slack, on the contrary, possesses a $\beta$ value of -0.2 or $(1-1.2)$. Hence, as per the propositions stated before it has to be classified as an inefficient DMU with an SE score of $\left(\frac{1}{1.2}\right)$ or 0.833 . The first step identifies the optimal location of the worst point at $(14.9,0.1)$ (as $\delta_{\tau=10}$ is found equivalent to $0.9)$. The second stage whereas results in deciphers the optimal scores of $\tau$ while incorporating this information (shown in Tab. 4).

The SE scores of $A, B, C, D, E$ and $F$ are computed as 1.127, 1.052, 1, 1.064, 1.169 and 0.855 , respectively (as compared to the earlier scores 1.143, 1.063, 1, 1.076, 1.200, 0.833 which were obtained from the choice of $\delta=\tau=0$ ). It can therefore be inferred that the SE scores of the Super-Efficient DMUs will deteriorate when a Worst Point is chosen as a basis of the reference. On the contrary, the opposite trend is observed for the Inefficient DMU. 
TABLE 3. Optimal solution at $\delta=\tau=0$.

\begin{tabular}{|c|c|c|c|c|c|c|c|c|c|c|c|c|}
\hline \multirow[b]{2}{*}{ Variable } & \multicolumn{2}{|c|}{ A } & \multicolumn{2}{|c|}{ B } & \multicolumn{2}{|c|}{$\mathrm{C}$} & \multicolumn{2}{|c|}{ D } & \multicolumn{2}{|c|}{$\mathrm{E}$} & \multicolumn{2}{|c|}{$\mathrm{F}$} \\
\hline & Value & $\begin{array}{l}\text { Reduced } \\
\text { cost }\end{array}$ & Value & $\begin{array}{l}\text { Reduced } \\
\text { cost }\end{array}$ & Value & $\begin{array}{l}\text { Reduced } \\
\text { cost }\end{array}$ & Value & $\begin{array}{l}\text { Reduced } \\
\text { cost }\end{array}$ & Value & $\begin{array}{l}\text { Reduced } \\
\text { cost }\end{array}$ & Value & $\begin{array}{l}\text { Reduced } \\
\text { cost }\end{array}$ \\
\hline$\tau$ & 0.875 & 0.000 & 0.941 & 0.000 & 1.000 & 0.000 & 0.929 & 0.000 & 0.833 & 0.000 & 1.200 & 0.000 \\
\hline$\lambda_{1}$ & 0.000 & 0.000 & 0.529 & 0.000 & 0.000 & 0.111 & 0.000 & 0.357 & 0.000 & 0.833 & 0.000 & 1.200 \\
\hline$\lambda_{2}$ & 1.000 & 0.000 & 0.000 & 0.000 & 0.333 & 0.000 & 0.000 & 0.143 & 0.000 & 0.500 & 0.000 & 0.800 \\
\hline$\lambda_{3}$ & 0.000 & 0.250 & 0.471 & 0.000 & 0.000 & 0.000 & 0.679 & 0.000 & 0.000 & 0.167 & 0.000 & 0.400 \\
\hline$\lambda_{4}$ & 0.000 & 0.375 & 0.000 & 0.029 & 0.667 & 0.000 & 0.000 & 0.000 & 1.000 & 0.000 & 0.000 & 0.200 \\
\hline$\lambda_{5}$ & 0.000 & 0.750 & 0.000 & 0.294 & 0.000 & 0.222 & 0.321 & 0.000 & 0.000 & 0.000 & 1.000 & 0.000 \\
\hline$\lambda_{6}$ & 0.000 & 0.875 & 0.000 & 0.500 & 0.000 & 0.444 & 0.000 & 0.214 & 0.000 & 0.000 & 0.000 & 0.000 \\
\hline Row & $\begin{array}{l}\text { Slack or } \\
\text { surplus }\end{array}$ & $\begin{array}{l}\text { Dual } \\
\text { price }\end{array}$ & $\begin{array}{l}\text { Slack or } \\
\text { surplus }\end{array}$ & $\begin{array}{l}\text { Dual } \\
\text { price }\end{array}$ & $\begin{array}{l}\text { Slack or } \\
\text { surplus }\end{array}$ & $\begin{array}{l}\text { Dual } \\
\text { price }\end{array}$ & $\begin{array}{l}\text { Slack or } \\
\text { surplus }\end{array}$ & $\begin{array}{l}\text { Dual } \\
\text { price }\end{array}$ & $\begin{array}{l}\text { Slack or } \\
\text { surplus }\end{array}$ & $\begin{array}{l}\text { Dual } \\
\text { price }\end{array}$ & $\begin{array}{l}\text { Slack or } \\
\text { surplus }\end{array}$ & $\begin{array}{l}\text { Dual } \\
\text { price }\end{array}$ \\
\hline 1.000 & 0.875 & 1.000 & 0.941 & 1.000 & 1.000 & 1.000 & 0.929 & 1.000 & 0.833 & 1.000 & 1.200 & 1.000 \\
\hline 2.000 & 0.000 & 0.125 & 0.000 & 0.118 & 0.000 & 0.111 & 0.000 & 0.071 & 3.167 & 0.000 & 1.000 & 0.000 \\
\hline 3.000 & 2.000 & 0.000 & 0.000 & -0.088 & 0.000 & -0.111 & 0.000 & -0.143 & 0.000 & -0.167 & 0.000 & -0.200 \\
\hline 4.000 & 0.000 & -0.875 & 0.000 & -0.618 & 0.000 & -0.444 & 0.000 & 0.071 & 0.000 & 1.000 & 0.000 & 1.400 \\
\hline 5.000 & 0.000 & 0.125 & 0.000 & 0.059 & 0.000 & 0.000 & 0.000 & 0.071 & 0.000 & 0.167 & 0.000 & -0.200 \\
\hline
\end{tabular}

TABLE 4. Optimal solution at $\delta=0.9$.

\begin{tabular}{|c|c|c|c|c|c|c|c|c|c|c|c|c|}
\hline \multirow[b]{2}{*}{ Variable } & \multicolumn{2}{|c|}{$\mathrm{A}$} & \multicolumn{2}{|c|}{ B } & \multicolumn{2}{|c|}{$\mathrm{C}$} & \multicolumn{2}{|c|}{$\mathrm{D}$} & \multicolumn{2}{|c|}{$\mathrm{E}$} & \multicolumn{2}{|c|}{$\mathrm{F}$} \\
\hline & Value & $\begin{array}{l}\text { Reduced } \\
\text { cost }\end{array}$ & Value & $\begin{array}{l}\text { Reduced } \\
\text { cost }\end{array}$ & Value & $\begin{array}{l}\text { Reduced } \\
\text { cost }\end{array}$ & Value & $\begin{array}{l}\text { Reduced } \\
\text { cost }\end{array}$ & Value & $\begin{array}{l}\text { Reduced } \\
\text { cost }\end{array}$ & Value & $\begin{array}{l}\text { Reduced } \\
\text { cost }\end{array}$ \\
\hline$\tau$ & 0.888 & 0.000 & 0.950 & 0.000 & 1.000 & 0.000 & 0.940 & 0.000 & 0.855 & 0.000 & 1.169 & 0.000 \\
\hline$\lambda_{1}$ & 0.000 & 0.000 & 0.536 & 0.000 & 0.000 & 0.093 & 0.000 & 0.299 & 0.000 & 0.725 & 0.000 & 1.017 \\
\hline$\lambda_{2}$ & 1.000 & 0.000 & 0.000 & 0.000 & 0.333 & 0.000 & 0.000 & 0.120 & 0.000 & 0.435 & 0.000 & 0.678 \\
\hline$\lambda_{3}$ & 0.000 & 0.225 & 0.464 & 0.000 & 0.000 & 0.000 & 0.677 & 0.000 & 0.000 & 0.145 & 0.000 & 0.339 \\
\hline$\lambda_{4}$ & 0.000 & 0.337 & 0.000 & 0.025 & 0.667 & 0.000 & 0.000 & 0.000 & 1.000 & 0.000 & 0.000 & 0.169 \\
\hline$\lambda_{5}$ & 0.000 & 0.674 & 0.000 & 0.248 & 0.000 & 0.185 & 0.323 & 0.000 & 0.000 & 0.000 & 1.000 & 0.000 \\
\hline$\lambda_{6}$ & 0.000 & 0.787 & 0.000 & 0.422 & 0.000 & 0.370 & 0.000 & 0.180 & 0.000 & 0.000 & 0.000 & 0.000 \\
\hline Row & $\begin{array}{l}\text { Slack or } \\
\text { surplus }\end{array}$ & $\begin{array}{l}\text { Dual } \\
\text { price }\end{array}$ & $\begin{array}{l}\text { Slack or } \\
\text { surplus }\end{array}$ & $\begin{array}{l}\text { Dual } \\
\text { price }\end{array}$ & $\begin{array}{l}\text { Slack or } \\
\text { surplus }\end{array}$ & $\begin{array}{l}\text { Dual } \\
\text { price }\end{array}$ & $\begin{array}{l}\text { Slack or } \\
\text { surplus }\end{array}$ & $\begin{array}{l}\text { Dual } \\
\text { price }\end{array}$ & $\begin{array}{l}\text { Slack or } \\
\text { surplus }\end{array}$ & $\begin{array}{l}\text { Dual } \\
\text { price }\end{array}$ & $\begin{array}{l}\text { Slack or } \\
\text { surplus }\end{array}$ & $\begin{array}{l}\text { Dual } \\
\text { price }\end{array}$ \\
\hline 1.000 & 0.888 & 1.000 & 0.950 & 1.000 & 1.000 & 1.000 & 0.940 & 1.000 & 0.855 & 1.000 & 1.169 & 1.000 \\
\hline 2.000 & 0.000 & 0.112 & 0.000 & 0.099 & 0.000 & 0.093 & 0.000 & 0.060 & 3.275 & 0.000 & 0.847 & 0.000 \\
\hline 3.000 & 2.101 & 0.000 & 0.000 & -0.074 & 0.000 & -0.093 & 0.000 & -0.120 & 0.000 & -0.145 & 0.000 & -0.169 \\
\hline 4.000 & 0.000 & -0.787 & 0.000 & -0.521 & 0.000 & -0.370 & 0.000 & 0.060 & 0.000 & 0.870 & 0.000 & 1.186 \\
\hline 5.000 & 0.000 & 0.112 & 0.000 & 0.050 & 0.000 & 0.000 & 0.000 & 0.060 & 0.000 & 0.145 & 0.000 & -0.169 \\
\hline
\end{tabular}

\section{Case studies}

Case 1. To verify the performance vis-à-vis other models the data set (Tab. 5) of the 15 US cities having three inputs, namely, high-end housing price (1000 US\$), lower-end housing monthly rental (US\$), and number of violent crimes, and three outputs, namely, median household income (US\$), number of bachelor's degrees (million) held by persons in the population, and number of doctors (thousand) from Seiford and Zhu [27] are analysed.

The modified version of the Input and Output oriented models prescribed by Cook et al. [9] could explain the level of super-efficiency scores of those DMUs which had infeasibility problems while employing the input-oriented and output-oriented SE BCC models (the columns showing Models 1 and 2 in Tab. 6). Philadelphia, Raleigh, St-Louis were able to achieve high scores due to the provisions of output reduction or input augmentation. One question will always be raised after this observing these outputs that is whether the model will be strong enough to handle negative data. For example, in presence of any negative input or output the direction vector may lose its power to select the peer on the production frontier. 
TABLE 5. 15 of Fortune's top US cities in 1996 (from [9]).

\begin{tabular}{lllllll}
\hline \hline City & $\begin{array}{l}\text { House } \\
\text { price }\end{array}$ & Rental & Violent & Income & $\begin{array}{l}\text { B. } \\
\text { Degree }\end{array}$ & Doctor \\
\hline Seattle & 586 & 581 & 1193.06 & 46928 & 0.6534 & 9.878 \\
Denver & 475 & 558 & 1131.64 & 42879 & 0.5529 & 5.301 \\
Philadelphia & 201 & 600 & 3468 & 43576 & 1.135 & 18.2 \\
Minneapolis & 299 & 609 & 1340.55 & 45673 & 0.729 & 7.209 \\
Raleigh & 318 & 613 & 634.7 & 40990 & 0.319 & 4.94 \\
StLouis & 265 & 558 & 657.5 & 39079 & 0.515 & 8.5 \\
Cincinnati & 467 & 580 & 882.4 & 38455 & 0.3184 & 4.48 \\
Washington & 583 & 625 & 3286.7 & 54291 & 1.7158 & 15.41 \\
Pittsburgh & 347 & 535 & 917.04 & 34534 & 0.4512 & 8.784 \\
Dallas & 296 & 650 & 3714.3 & 41984 & 1.2195 & 8.82 \\
Atlanta & 600 & 740 & 2963.1 & 43249 & 0.9205 & 7.805 \\
Baltimore & 575 & 775 & 3240.75 & 43291 & 0.5825 & 10.05 \\
Boston & 351 & 888 & 2197.12 & 46444 & 1.04 & 18.208 \\
Milwaukee & 283 & 727 & 778.35 & 41841 & 0.321 & 4.665 \\
Nashville & 431 & 695 & 1245.75 & 40221 & 0.2365 & 3.575 \\
\hline
\end{tabular}

TABLE 6. Comparison of Super Efficiency Scores.

\begin{tabular}{lllllll}
\hline \hline DMU & City & Model 1 & Model 2 & $\begin{array}{l}\text { Proposed } \\
\text { model }\end{array}$ & SE & $\begin{array}{l}\text { Rank of } \\
\text { Prop-model }\end{array}$ \\
\hline DMU1 & Seattle & 1.44335 & 1.0934 & 0.11897 & 1.14 & 6 \\
DMU2 & Denver & 1.01593 & 1.0527 & 0.02468 & 1.03 & 10 \\
DMU3 & Philadelphia & Infeasible & Infeasible & 0.34116 & 1.52 & 2 \\
DMU4 & Minneapolis & 1.22752 & 1.086 & 0.12986 & 1.15 & 5 \\
DMU5 & Raleigh & 1.16766 & Infeasible & 0.03635 & 1.04 & 8 \\
DMU6 & StLouis & 1.51628 & Infeasible & 0.13835 & 1.16 & 4 \\
DMU7 & Cincinnati & 0.94968 & 0.897 & -0.075 & 0.93 & 12 \\
DMU8 & Washington & Infeasible & 1.5344 & 0.45381 & 1.83 & 1 \\
DMU9 & Pittsburgh & 1.04529 & Infeasible & 0.06516 & 1.07 & 7 \\
DMU10 & Dallas & 0.92652 & 0.9532 & -0.0415 & 0.96 & 11 \\
DMU11 & Atlanta & 0.77243 & 0.8137 & -0.6304 & 0.61 & 14 \\
DMU12 & Baltimore & 0.73827 & 0.8009 & -0.8664 & 0.54 & 15 \\
DMU13 & Boston & Infeasible & 1.3181 & 0.22675 & 1.29 & 3 \\
DMU14 & Milwaukee & 1.06559 & 1.0276 & 0.02651 & 1.03 & 9 \\
DMU15 & Nashville & 0.80117 & 0.873 & -0.2275 & 0.81 & 13 \\
\hline
\end{tabular}

On the contrary, it is observed that none of these cities is posing any infeasibility problem during the application of the proposed model (PM column of Tab. 6). Whether it remains inside or outside the proposed model will offer an appropriate solution.

In addition to that, the discrimination of the superefficient members from the inefficient members (as mentioned in [9]) is accomplished while noticing the signs of $\beta$. Moreover, consolidated SE scores are obtained without having any glitches (of finding very high SE scores).

Case 2. The data set (Tab. 7) of Byrnes et al. [3] is taken into account here to analyse the benefits of the proposed model vis-a-vis the methods of Ray [26], Lee and Zhu [18] and Lin and Chen [20]. The results found in Table 8 revealed the weakness of Ray [26] to eliminate the infeasibility problem. But, in this 
TABle 7. Data for Case 2.

\begin{tabular}{llllllllll}
\hline \hline DMU & Labor & $K 1$ & $K 2$ & $K 3$ & $T 1$ & $1 / D 1$ & $T 2$ & $1 / D 2$ & Out \\
\hline 1 & 98.5 & 142 & 245 & 0 & 6 & 0.016 & 4.3 & 0.012 & 3264 \\
2 & 96.5 & 30 & 215 & 0 & 6 & 0.016 & 0 & 0 & 3065 \\
3 & 57.6 & 18 & 105 & 0 & 5.6 & 0.026 & 4.2 & 0.016 & 2275 \\
4 & 59.2 & 160 & 0 & 0 & 5.9 & 0.025 & 3.7 & 0.011 & 1978 \\
5 & 57.6 & 200 & 0 & 0 & 8 & 0.022 & 3.5 & 0.011 & 1833 \\
6 & 49.9 & 27 & 85 & 0 & 4.5 & 0.019 & 0 & 0 & 1218 \\
7 & 53.5 & 143 & 65 & 0 & 6 & 0.01 & 0 & 0 & 928 \\
8 & 34 & 70 & 65 & 12 & 6 & 0.02 & 5 & 0.01 & 919 \\
9 & 39.6 & 67.5 & 40 & 0 & 6.5 & 0.013 & 0 & 0 & 777 \\
10 & 51.3 & 0 & 145 & 0 & 3.2 & 0.019 & 0 & 0 & 745 \\
11 & 74.2 & 110 & 65 & 0 & 2.1 & 0.014 & 0 & 0 & 742 \\
12 & 24 & 25 & 65 & 0 & 4.4 & 0.012 & 0 & 0 & 488 \\
13 & 26.5 & 58 & 0 & 0 & 3 & 0.014 & 0 & 0 & 407 \\
14 & 43.1 & 70 & 0 & 0 & 6.5 & 0.012 & 0 & 0 & 402 \\
15 & 20.7 & 236 & 0 & 0 & 5.7 & 0.01 & 0 & 0 & 396 \\
\hline
\end{tabular}

TABLE 8. Comparison of optimal scores from various models.

\begin{tabular}{lllllll}
\hline \hline DMUs & $\begin{array}{l}\text { SE score } \\
\text { from } \\
\text { BCC }\end{array}$ & $\begin{array}{l}\text { Tau } \\
\text { value } \\
\text { from } \\
(3.6 \mathrm{~b})\end{array}$ & $\begin{array}{l}\text { SE score } \\
\text { from } \\
(3.6 \mathrm{c})\end{array}$ & $\begin{array}{l}\text { SE } \\
\text { scores } \\
{[18]}\end{array}$ & $\begin{array}{l}\text { Beta value } \\
\text { from Ray }\end{array}$ & $\begin{array}{l}\text { Beta value } \\
\text { from Lin }\end{array}$ \\
\hline DM1 & Infeasible & 0.931 & 1.075 & 2.0649 & -0.061 & -0.069 \\
DM2 & Infeasible & 0.634 & 1.577 & 3.7039 & -0.603 & -0.188 \\
DM3 & 1.5473 & 0.836 & 1.196 & 1.5473 & -0.270 & -0.041 \\
DM4 & Infeasible & 0.845 & 1.183 & 2.4350 & -0.203 & -0.041 \\
DM5 & 1.7038 & 0.959 & 1.043 & 1.0738 & -0.041 & -0.009 \\
DM6 & 1.1598 & 0.968 & 1.033 & 1.1598 & -0.102 & -0.009 \\
DM7 & 1.1468 & 0.907 & 1.102 & 1.1468 & -0.130 & -0.017 \\
DM8 & 0.9375 & 1.027 & 0.973 & 0.9374 & 0.043 & 0.006 \\
DM9 & 1.0014 & 0.999 & 1.001 & 1.0014 & -0.001 & 0.000 \\
DM10 & Infeasible & 0.843 & 1.186 & 2.5329 & Infeasible & -0.041 \\
DM11 & 1.5543 & 0.811 & 1.233 & 1.5543 & -0.433 & -0.044 \\
DM12 & 1.4788 & 0.859 & 1.165 & 1.4782 & -0.479 & -0.031 \\
DM13 & Infeasible & 0.799 & 1.252 & 3.1680 & -1.085 & -0.052 \\
DM14 & 1.1275 & 0.939 & 1.065 & 1.1274 & -0.127 & -0.012 \\
DM15 & 1.3761 & 0.863 & 1.159 & 1.3760 & -0.376 & -0.031 \\
\hline
\end{tabular}

context, the method of Lin and Chen [20] remained successful after incorporating the Big-M approach. Both models, however, fail to produce positive values of $\tau$ and thus require further steps to determine SE scores. On the contrary, the prescribed model stresses on selecting a worst point located very close to the vector $\left[x_{1 \max } x_{2 \max } \ldots x_{m \max }, y_{1 \min } y_{2 \min } \ldots y_{v \min }\right]$. None of the DMUs could pose any infeasibility problem during the application of (3.6b) even after feeding the optimal value of $\delta=0.0002$ derived from solving (3.6a) (for $\tau=99$ ). The optimal values of $\tau$ always remained positive and never offered any hurdle for computing SE scores. Apart from that these scores have a rank correlation of $88 \%$ with those ones obtained from the model of Lee and Zhu [18] (shown in the 5th column of Tab. 8). 


\section{Discussion AND CONCLUSION}

The major strength of this model is ability to detect a superefficient firm from the sign of $\tau$. The SE score always remains positive during the evaluation of an efficient or inefficient DMU. Barring this, the impact of selecting a worst point from the $\delta$-neighbourhood on the efficiency scores can be explained. In this context, the initial value of $\tau$ is instrumental.

The proposed model is unit invariant. The constraint $\sum_{\substack{r=1 \\ r \neq o}}^{c} x_{i r} \lambda_{r} \leq x_{i o}+(1-\tau)\left(\bar{x}_{o}-x_{i o}\right)$ remains unchanged when $x_{i r}, \bar{x}_{o}$ and $x_{i o}$ are replaced by $Q x_{i r}, Q \bar{x}_{o}$ and $Q x_{i o}$ and never makes any impact on the efficiency score. Under VRS $\left(\sum_{\substack{r=1 \\ r \neq 0}}^{c} \lambda_{r}=1, \lambda_{r} \geq 0\right)$ assumption the model also becomes translation invariant. Thus, any change made in any $i$ th input to an amount of $\eta$ is not going to produce a new constraint. Incorporating these changes into the $i$ th input constraint of the proposed model the following one is created:

$$
\sum_{\substack{r=1 \\ r \neq 0}}^{c}\left(x_{i r}+\eta\right) \lambda_{r} \leq\left(x_{i o}+\eta\right)+(1-\tau)\left(\bar{x}_{o}+\eta-x_{i o}-\eta\right) .
$$

But, due to the VRS assumption this constraint remains similar to the original one cited in (3.4): $\sum_{\substack{r \neq 1 \\ r \neq 0}}^{c} x_{i r} \lambda_{r} \leq$ $x_{i o}+(1-\tau)\left(\bar{x}_{o}-x_{i o}\right)$. Hence, the model can handle the negative data. Lastly, the extant paper finds an expression of SE which symbolises the radial savings of all inputs and radial surplus of all outputs simultaneously.

Acknowledgements. Prof. Emrouznezad Ali has been my inspiration to unravel new aspects. apart from that, i must appreciate the referees and the eminent editors for giving me ample scope for making changes to improve the paper.

\section{Appendix A.}

Theorem A.1. A Super-efficient DMUs (Excluding the Strongly Super-efficient members) are those which offers an optimal output $\beta \geq 0$ with all zero slacks in the model depicted in (3.6a).

Proof. A Super-efficient DMU is the one which remains feasible and does not carry any slack when it is treated under an Input or output oriented BCC DEA model. In other words, non-existence of slack is observed as the peer appears from the optimal solution is located on the frontier. In this context, the following assumptions are necessary for the Super-efficient DMU under consideration when VRS technology is seen:

$$
x_{i \min }<x_{i o}<x_{i \max }, \quad i=1,2, \ldots, m .
$$

Here, $x_{i \min }=\min _{r \neq O} x_{i r}, x_{i \max }=\max _{r \neq O} x_{i r}$

$$
\begin{array}{ll}
y_{j \min }<y_{j o}<y_{j \max } & j=1,2, \ldots, v \\
y_{j \min }=\min _{r \neq O} y_{j r}, y_{j \max }=\max _{r \neq O} y_{j r} & \\
\sum_{\substack{r=1 \\
r \neq o}}^{c} x_{i r} \lambda_{r} \geq x_{i o}, & \\
\sum_{\substack{r=1 \\
r \neq o}}^{c} y_{j r} \lambda_{r} \leq y_{j o}, & \\
\sum_{\substack{r=1 \\
r \neq o}}^{c} \lambda_{r}=1, & \text { for } r=1,2 \ldots, c, r \neq o .
\end{array}
$$


Now due to convexity rules the subsequent inequalities gets established:

$$
\begin{aligned}
x_{i \max }+\delta>x_{i \max }>\sum_{\substack{r=1 \\
r \neq o}}^{c} x_{i r} \lambda_{r} \geq x_{i o}, \quad \forall i, r \\
y_{j \text { min }}-\delta<y_{j \text { min }}<\sum_{\substack{r=1 \\
r \neq 0}}^{c} y_{j r} \lambda_{r} \leq y_{j o}, \quad \forall j, r .
\end{aligned}
$$

Now, according to the Theorem 3.3 the DMU has to remain away from the PPS and hence, the line drawn from it to connect the worst point has to intersect the production frontier. Since any point on the frontier can be specified by the convex sum of all weighed input and output so for a value of $\lambda_{r}=\lambda_{r}^{*}$ the following equality can be possible:

$$
\begin{array}{ll}
\sum_{\substack{r=1 \\
r \neq o}}^{c} x_{i r} \lambda_{r}^{*}=\tau x_{i o}+(1-\tau)\left(x_{i \max }+\delta^{\prime}\right), & \forall i, r \\
\sum_{\substack{r=1 \\
r \neq o}}^{c} y_{j r} \lambda_{r}^{*}=\tau y_{j o}+(1-\tau)\left(y_{j \min }-\delta^{\prime}\right) & \forall j, r .
\end{array}
$$

At $\tau=0(\tau=1)$ the right hand-side has a greatest (lowest) total of $\left(x_{i \max }+\delta^{\prime}\right)\left[\left(x_{i o}\right)\right]$. Hence, the peer can be traced in between the maximum and the minimum value due to $\tau$ having a restricted within $1>\tau>0$. In other words, $\tau$ has to be strictly positive.

Theorem A.2. Any DMU will be termed as Inefficient if it gives rise to an optimal output $\beta<0$ when treated with the model (3.6a).

Proof. An inefficient DMU is retained within the zone owing to the propositions described to create the PPS. Observing the property within PPS, an Inefficient DMU has to allow the subsequent input and output constraints:

$$
\begin{array}{ll}
\sum_{\substack{r=1 \\
r \neq o}}^{c} x_{i r} \lambda_{r}=x_{i o}-S_{i}, & i=1,2, \ldots, m \\
\sum_{\substack{r=1 \\
r \neq 0}}^{c} y_{j r} \lambda_{r}=y_{j o}+S_{j}, & j=1,2, \ldots, v \\
S_{i} \geq 0 \text { and } S_{j} \geq 0, & \forall i, j .
\end{array}
$$

Now, considering the optimal value $\tau^{\prime}$ from the proposed model (3.6a) it can be stated that

$$
\begin{aligned}
& -\left(1-\tau^{\prime}\right)\left(x_{i \max }+\delta^{\prime}-x_{i o}\right) \geq S_{i} \geq 0 \\
& -\left(1-\tau^{\prime}\right)\left(y_{j o}-y_{j \min }+\delta^{\prime}\right) \geq S_{j} \geq 0 .
\end{aligned}
$$

The left hand side in these inequalities can only remain positive if and only if $\left(1-\tau^{\prime}\right)$ becomes negative (or $\left.\beta_{o}=\left(1-\tau^{\prime}\right)<0\right)$.

Theorem A.3. Any DMU will be termed as a strongly Super-efficient if it gives rise to an optimal output $\beta>0$ when treated with the model (3.6a). 
Proof. A strongly Super-efficient DMU is the one which ends up with an infeasibility crisis when it is treated under an Input or output oriented BCC DEA model. Such a unit needs to have at least one extraordinary output (input) which is larger (smaller) than the peer obtained from the analysis. In other words, for any DMU which satisfies the following inequality conditions strictly for at least one value of $i$ and (or) $j$ will be called as a strongly Super-efficient DMU.

$$
\begin{array}{ll}
x_{i \min }<x_{i o}<x_{i \max }, & i=1,2, \ldots, m, i \neq t \\
x_{i o}<x_{i \min }<x_{i \max }, & i=t .
\end{array}
$$

Here, $x_{i \min }=\min _{r \neq O} x_{i r}, x_{i \max }=\max _{r \neq O} x_{i r}$

$$
\begin{array}{ll}
y_{j \min }<y_{j o}<y_{j \max } & j=1,2, \ldots, v, j \neq f \\
y_{j \min }<y_{j \max }<y_{j o} & j=f \\
y_{j \min }=\min _{r \neq 0} y_{j r}, y_{j \max }=\max _{r \neq O} y_{j r} . &
\end{array}
$$

Let there exists an optimal value $\tau=\tau^{\prime}$ such that for the optimal value of the intensity variable $\lambda_{r}=\lambda_{r}^{*}$ the following equality can be possible when $\forall i \neq t, r \neq f$ :

$$
\begin{array}{ll}
\sum_{\substack{r=1 \\
r \neq o}}^{c} x_{i r} \lambda_{r}^{*}=\tau^{\prime} x_{i o}+\left(1-\tau^{\prime}\right)\left(x_{i \max }+\delta^{\prime}\right), & \forall i, r \\
\sum_{\substack{r=1 \\
r \neq o}}^{c} y_{j r} \lambda_{r}^{*}=\tau^{\prime} y_{j o}+\left(1-\tau^{\prime}\right)\left(y_{j \min }-\delta^{\prime}\right), & \forall j, r .
\end{array}
$$

Strongly super-efficient DMU has to have all properties possessed by a super-efficient DMU. Hence, the condition of $\left(1-\tau^{\prime}\right)>0$ has to be fulfilled. However, such equalities cannot be maintained at the time of $i=t, r=f$ due to following reason. Such extraordinary cases are seen for only Super-efficient DMUs:

$$
\begin{array}{ll}
x_{i o}<x_{i \min }<x_{i \max }, & i=t \\
y_{j \min }<y_{j \max }<y_{j o}, & j=f .
\end{array}
$$

Now, owing to the optimal solution $\tau=\tau^{\prime}$ and $\lambda_{r}=\lambda_{r}^{*}$ along with the convexity assumptions the corresponding the following inequalities are obtained:

$$
\begin{aligned}
& x_{i o}<x_{i \min } \leq \sum_{\substack{r=1 \\
r \neq o}}^{c} x_{i r} \lambda_{r}^{*}=\tau^{\prime} x_{i o}+\left(1-\tau^{\prime}\right)\left(x_{i \max }+\delta^{\prime}\right) \leq x_{i \max }, \quad i=t \\
& y_{j \min } \leq \sum_{\substack{r=1 \\
r \neq o}}^{c} y_{j r} \lambda_{r}^{*}=\tau^{\prime} y_{j o}+\left(1-\tau^{\prime}\right)\left(y_{j \min }-\delta^{\prime}\right) \leq y_{j \max }<y_{j o}, \quad j=f .
\end{aligned}
$$

In other words, non-zero slacks are seen in these two cases:

$$
\begin{array}{ll}
x_{t o}+S_{t}=\sum_{\substack{r=1 \\
r \neq o}}^{c} x_{t r} \lambda_{r}^{*}, & i=t \\
\sum_{\substack{r=1 \\
r \neq o}}^{c} y_{j r} \lambda_{r}^{*}+S_{f}=y_{j o} & j=f
\end{array}
$$




$$
S_{f}, S_{f}>0
$$

Hence, it is proved that any strongly Super-efficient DMU has to offer $\left(1-\tau^{\prime}\right)>0$ and at least one non-zero input or output slack.

Acknowledgements. Prof. Emrouznezad Ali has been my inspiration to unravel new aspects. Apart from that, I appreciate the referees and the eminent editors for giving me ample scope for making changes to improve the paper.

\section{REFERENCES}

[1] P. Anderson and N.C. Peterson, A procedure for ranking efficient units in data envelopment analysis. Manage. Sci. 39 (1993) 1261-1264.

[2] M.S. Bazaraa, H.D. Sherali and C.M. Shetty, Nonlinear Programming: Theory and Algorithms, 3rd edition. John Wiley and Sons (2006).

[3] P. Byrnes, R. Fare and S. Grosskopf. Measuring productive efficiency: An application to Illinois strip mines. Manag. Sci. 30 (1984) 671-681

[4] R.G. Chambers, Y. Chung and R. Färe, Benefit and distance functions. J. Econ. Theory 70 (1996) $407-419$.

[5] A. Charnes, W.W. Cooper and E. Rhodes, Measuring the efficiency of decision making units. Eur. J. Oper. Res. 2 (1978) 429-444.

[6] Y. Chen, Measuring super-efficiency in DEA in the presence of infeasibility. Eur. J. Oper. Res. 161 (2005) $545-551$.

[7] Y. Chen, J. Du and J. Huo, Super-efficiency based on a modified directional distance function. Omega 41 (2013) 621-625.

[8] Y. Chen and L. Liang. Super-efficiency DEA in the presence of infeasibility: One model approach. Eur. J. Oper. Res. 213 (2011), 359-360.

[9] W.D. Cook, L. Liang, Y. Zha and J. Zhu, A modified super-efficiency DEA model for infeasibility. J. Oper. Res. Soc. 60 (2009) $276-281$.

[10] J. Doyle and R. Green, Data envelopment analysis and multiple criteria decision making. Omega 21 (1993) $713-715$.

[11] J. Doyle and R. Green, Efficiency and cross-efficiency in DEA: derivations, meanings and uses. J. Oper. Res. Soc. 45 (1994) $567-578$.

[12] J. Du, C. Chen, Y. Chen, W.D. Cook and J. Zhu, Additive super-efficiency in integer-valued data envelopment analysis. Eur. J. Oper. Res. 218 (2012) 186-192.

[13] A. Emrouznejad, A.L. Anouze and E. Thanassoulis, A semi-oriented radial measure for measuring the efficiency of decision making units with negative data, using DEA. Eur. J. Oper. Res. 200 (2010) 297-304.

[14] M. Gnewuch and K. Wohlrabe, Super-efficiency of education institutions: an application to economics departments. Edu. Econ. 26 (2018) 610-623.

[15] A. Hadi-Vencheh and A. Esmaeilzadeh, A new super-efficiency model in the presence of negative data. J. Oper. Res. Soc. 64 (2013) 396-401.

[16] M. Halme, T. Pro and M. Koivu, Dealing with interval-scale data in data envelopment analysis. Eur. J. Oper. Res. 137 (2002) $22-27$.

[17] H. S. Lee, C. W. Chu, and J. Zhu. Super-efficiency DEA in the presence of infeasibility. Eur. J. Oper. Res. 212 (2011), $141-147$.

[18] H.S. Lee and J. Zhu, Super-efficiency infeasibility and zero data in DEA. Eur. J. Oper. Res. 216 (2012) $429-433$.

[19] R. Lin and Z. Chen, Super-efficiency measurement under variable return to scale: an approach based on a new directional distance function. J. Oper. Res. Soc. 66 (2015) 1506-1510.

[20] R. Lin and Z. Chen, A directional distance-based super-efficiency DEA model handling negative data. J. Oper. Res. Soc. 68 (2017) 1312-1322.

[21] R. Lin and Y. Liu, Super-efficiency based on the directional distance function in the presence of negative data. Omega 85 (2019) 26-34.

[22] C.A.K. Lovell and A.P.B. Rouse, Equivalent standard DEA models to provide super-efficiency scores. J. Oper. Res. Soc. 54 (2003) 101-108.

[23] R.K. Matin and R.K. Azizi, Modified semi-oriented Radial Measure for measuring the efficiency of DMUs. In: With 3rd Operation, Research Conference (2010).

[24] J.T. Pastor, Translation invariance in data envelopment analysis: a generalization. Ann. Oper. Res. 66 (1996) 93-102.

[25] M.C.S. Portela, E. Thanassoulis and G. Simpson, Negative data in DEA: a directional distance approach applied to bank branches. J. Oper. Res. Soc. 55 (2004) 1111-1121.

[26] S. Ray, The directional distance function and measurement of super-efficiency: an application to airlines data. J. Oper. Res. Soc. 59 (2008) 788-797.

[27] L.M. Seiford and J. Zhu, Infeasibility of super-efficiency data envelopment analysis models. INFORS 37 (1999) $174-187$.

[28] J.A. Sharp, W. Meng and W. Liu, A modified slacks-based measure model for data envelopment analysis with natural negative outputs and inputs. J. Oper. Res. Soc. 57 (2007) 1-6.

[29] T.J. Stewart, Data envelopment analysis and multiple criteria decision-making - a response. Omega 22 (1994) $205-206$. 
[30] R.M. Thrall, Duality, classification and slacks in DEA. Ann. Oper. Res. 66 (1996) 109-138.

[31] C. Tofallis, Improving discernment in DEA using profiling. Omega 24 (1996) 361-364.

[32] K. Tone, A slacks-based measure of super-efficiency in data envelopment analysis. Eur. J. Oper. Res. 143 (2002) $32-41$.

[33] M. Xue and P.T. Harker, Note: ranking DMUs with infeasible super-efficiency DEA models. Manage. Sci. 48 (2002) $705-710$.

[34] S.H. Yu and C.W. Hsu, A unified extension of super-efficiency in additive data envelopment analysis with integer-valued inputs and outputs: an application to a municipal bus system. Ann. Oper. Res. 287 (2020) 515-535.

[35] J. Zhu, Robustness of the efficient DMUs in data envelopment analysis. Eur. J. Oper. Res. 90 (1996) $451-460$.

[36] J. Zhu, Super-efficiency and DEA sensitivity analysis. Eur. J. Oper. Res. 129 (2001) 443-455.

\section{Subscribe to Open (S20) A fair and sustainable open access model}

This journal is currently published in open access under a Subscribe-to-Open model (S2O). S2O is a transformative model that aims to move subscription journals to open access. Open access is the free, immediate, online availability of research articles combined with the rights to use these articles fully in the digital environment. We are thankful to our subscribers and sponsors for making it possible to publish this journal in open access, free of charge for authors.

\section{Please help to maintain this journal in open access!}

Check that your library subscribes to the journal, or make a personal donation to the S2O programme, by contacting subscribers@edpsciences.org

More information, including a list of sponsors and a financial transparency report, available at: https://www. edpsciences.org/en/maths-s2o-programme 